\title{
ChemComm
}

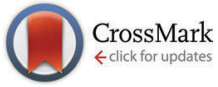

Cite this: Chem. Commun., 2017. 53,372

Received 2nd November 2016, Accepted 2nd December 2016

DOI: $10.1039 / c 6 c c 08798 a$

www.rsc.org/chemcomm

\section{Fenton's reagent for the rapid and efficient isolation of microplastics from wastewater}

\author{
A. S. Tagg, ${ }^{a}$ J. P. Harrison, ${ }^{b}$ Y. Ju-Nam, ${ }^{a}$ M. Sapp, ${ }^{C}$ E. L. Bradley, ${ }^{d}$ C. J. Sinclair ${ }^{d}$ and \\ J. J. Ojeda*a
}

Fenton's reagent was used to isolate microplastics from organicrich wastewater. The catalytic reaction did not affect microplastic chemistry or size, enabling its use as a pre-treatment method for focal plane array-based micro-FT-IR imaging. Compared with previously described microplastic treatment methods, Fenton's reagent offers a considerable reduction in sample preparation times.

Microplastics (plastic fragments with a commonly defined upper size limit of $5 \mathrm{~mm}$ ) have been a growing environmental pollution concern since the term was first described in $2004 .^{1}$ Although microplastics are relatively well-documented within marine and coastal environments, there is a lack of freshwater microplastic pollution studies. ${ }^{2,3}$ Further to this, there is a particular lack of studies investigating how microplastics are transported into unmanaged freshwaters from wastewater treatment facilities (WWTF), despite emerging evidence that substantial numbers of plastic fragments can pass through them. $^{4-7}$ For example, Hoellein et $a l^{8}$ found microplastic abundance to be higher downstream of a WWTF compared to upstream. In addition, Browne et al. ${ }^{9}$ demonstrated that large numbers of plastic fibres are released by washing machines. Recently, a limited number of studies have emerged investigating microplastics within WWTF. ${ }^{4,7}$ However, these studies have relied on visual sorting of putative plastic particles, which is open to bias, particularly when analysing organic-rich samples such as wastewater. To combat this bias, spectroscopic approaches have recently been developed. In particular, reflectance Fourier-transform infrared microspectroscopic (micro-FT-IR) imaging has been used to accurately detect microplastics in

\footnotetext{
${ }^{a}$ Systems and Process Engineering Centre, College of Engineering, Swansea University, Swansea, SA1 8EN, UK. E-mail:j.j.ojedaledo@swansea.ac.uk

${ }^{b}$ Division of Microbial Ecology, Department of Microbiology and Ecosystem Science, Research Network “Chemistry Meets Microbiology”, University of Vienna, Vienna, A-1090, Austria

Institute of Population Genetics, Heinrich Heine University, Düsseldorf, 40225, Germany

${ }^{d}$ Fera Science Ltd, Sand Hutton, York, YO41 1LZ, UK

$\dagger$ Electronic supplementary information (ESI) available. See DOI: 10.1039/c6cc08798a
}

wastewater samples without visual sorting. ${ }^{10}$ However, due to the intrinsic complexity of wastewater samples, pre-treatment steps to remove biogenic organic matter need to be performed before the spectroscopic analysis. The most successful pretreatment method up to date for isolating microplastics from wastewater (activated aerobic biological stage) involved a digestion step in which samples were exposed to $30 \%(\mathrm{v} / \mathrm{v}) \mathrm{H}_{2} \mathrm{O}_{2}$ for seven days. ${ }^{10}$ Although sufficient for analysing small sample volumes, larger samples of wastewater $(\geq 1$ l) or wastewater with increased levels of organic detritus may not be sufficiently treated by exposure to $\mathrm{H}_{2} \mathrm{O}_{2}$ alone. As such, there is a continuing need for microplastic pre-treatment methods that enable analysis of large sample volumes within a short timeframe. Such methods should also have a minimal impact on the surface chemistry and sizes of the microplastic fragments. Indeed, the precision of any spectroscopic method employed for the detection of microplastics relies on how the samples are prepared for analysis.

Owing to its ability to rapidly break down organic compounds through oxidation, Fenton's reagent (a mixture of $\mathrm{H}_{2} \mathrm{O}_{2}$ and ferrous ion, $\mathrm{Fe}^{2+}$ ) has been effectively used to purify wastewater. ${ }^{11}$ The Fenton reaction ${ }^{12}$ refers to an advanced oxidation process in which ferrous ion $\left(\mathrm{Fe}^{2+}\right)$ initiates and catalyses the decomposition of $\mathrm{H}_{2} \mathrm{O}_{2}$, leading to the in situ generation of hydroxyl and hydroperoxyl radicals:

$$
\mathrm{Fe}^{2+}+\mathrm{H}_{2} \mathrm{O}_{2} \rightarrow \mathrm{Fe}^{3+}+\cdot \mathrm{OH}+\mathrm{HO}^{-}
$$

Additionally to facilitating the efficient analysis of plastics in large volumes of wastewater, Fenton's reagent could enable the analysis of microplastics in other sample types that are challenging to analyse. For example, it could allow for the detection of these pollutants in soils or compost-like output (CLO) produced by WWTFs. The approach could also facilitate accurate analyses of microplastics in biological samples, such as gut or tissue sections. ${ }^{13}$ However, before Fenton's reagent can be recommended for use in microplastic research, it is important to ascertain whether the reaction can influence or bias the results of microplastic sampling, either by affecting the size of the fragments or by influencing the chemistry of the polymer backbone. The former 
issue is particularly relevant for identifying small microplastics $(<1 \mathrm{~mm})$, which could be destroyed by a stringent purification step or become impossible to identify using conventional spectroscopic techniques.

In this study, microplastics from four different polymer types (polyethylene, PE; polypropylene, PP; polyvinyl chloride, PVC; and nylon) were exposed to Fenton's reagent at three different doses of $\mathrm{H}_{2} \mathrm{O}_{2}$ and iron sulphate $\left(\mathrm{FeSO}_{4} \cdot 7 \mathrm{H}_{2} \mathrm{O}\right)$ as the ferrous ion source (VWR, Leicestershire, England). The different polymer types were selected based on their frequency of occurrence in studies of microplastic debris sampled at sea or in marine sediments. In a review of 42 studies by Hidalgo-Ruz et al. ${ }^{14} \mathrm{PE}$ and PP were recorded in 33 and 27 studies respectively (79\% and 64\% respectively); Nylon was detected in 7 studies (17\%); while PVC was observed in 2 studies (5\%).

The different doses of Fenton's reagent were dictated by the concentration of iron sulphate per ml of buffer $\left(10,20\right.$ or $30 \mathrm{mg} \mathrm{ml}^{-1}$ of $\mathrm{FeSO}_{4} \cdot 7 \mathrm{H}_{2} \mathrm{O}$ ). Each exposure was conducted in a $2 \mathrm{ml}$ centrifuge tube, using $1 \mathrm{ml}$ of $30 \%(\mathrm{v} / \mathrm{v}) \mathrm{H}_{2} \mathrm{O}_{2}$ mixed with $0.5 \mathrm{ml}$ of catalyst in a pH 5 solution. The final concentrations of $\mathrm{FeSO}_{4} \cdot 7 \mathrm{H}_{2} \mathrm{O}$ were $3.33,6.67$ and $10 \mathrm{mg} \mathrm{ml}^{-1}$, respectively. $0.01 \mathrm{~g}$ of each microplastic type was allowed to react with the solution for approximately 10 minutes until the reaction was complete. All experiments took place at room temperature. All exposures were performed in triplicate. Post-reaction microplastics were rinsed in water and $80 \%(\mathrm{v} / \mathrm{v})$ ethanol (VWR) prior to FT-IR analysis. Spectra of microplastics were obtained using a Spectrum One FT-IR spectroscope (Perkin-Elmer, UK) with a Specac Golden Gate diamond attenuated total reflectance (ATR) accessory (Specac, UK). Fifty co-added scans were performed per replicate, using a spectral resolution of $4 \mathrm{~cm}^{-1}$ and a wavenumber range of $4000-650 \mathrm{~cm}^{-1}$.

To investigate the impacts of Fenton's reagent on the size of the polymer particles, the $2 \mathrm{D}$ surface areas of at least 20 pre- and post-reaction fragments for each polymer type were calculated using the 'analyse particle' function available in the software package ImageJ (version 1.50g). ${ }^{15}$ Overlapping or partially obscured microplastics were omitted from size calculations. Original size data, including some example images, are included in the ESI. $\dagger$ Particle surface areas were compared against experimental controls (unexposed stock microplastics) using one-way analyses of variance (ANOVA) for each polymer type. The data for PE and nylon were natural log-transformed to meet linear model assumptions. A post hoc Tukey's Honestly Significant Difference (HSD) test was performed for the nylon data. All analyses were completed using R v. 3.2.1 ${ }^{16}$ with the Tukey HSD test performed using the library "agricolae". ${ }^{17}$ Additionally, the ATR-FT-IR spectra of control and Fenton's reagent-exposed particles were compared for all polymer types to determine whether sample treatment affected the presence and positions of key absorbance bands for plastic identification (see Tagg et al. ) $^{10}$

Treatment with Fenton's reagent had no significant influence on the surface areas of PE, PP and PVC microplastics (one-way ANOVAs performed for each polymer type, $p>0.05$; see Fig. 1). Even though none of the catalyst-treated sample groups differed significantly from the catalyst-free control (Fig. 1), the surface areas of nylon particles differed between sample groups a

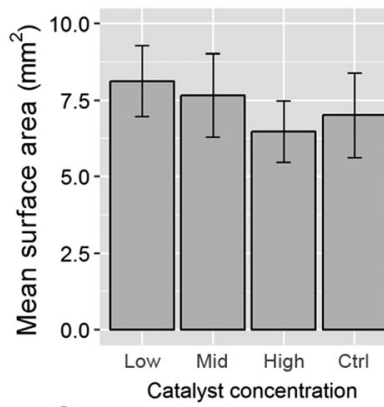

C

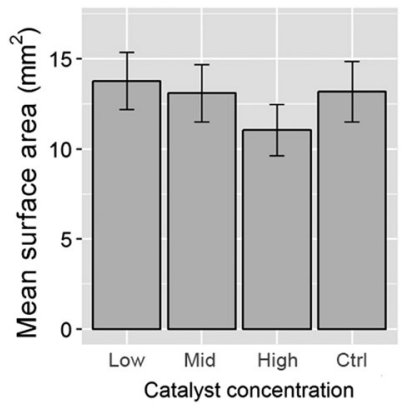

b

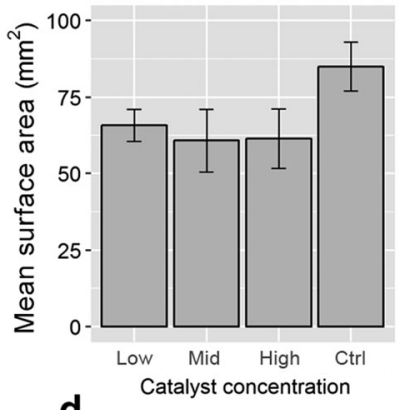

d

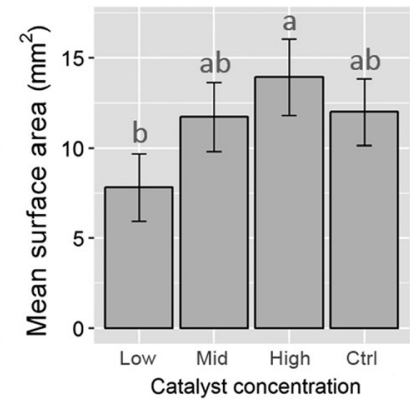

Fig. 1 Effect of Fenton's reagent on microplastic sizes of four polymer types: (a) PE; (b) PP; (c) PVC; (d) nylon. The data are given as untransformed means \pm standard errors of the means $(n=20)$. Different letters above the bars in panel (d) indicate significant differences between samples (Tukey's HSD test following one-way ANOVA).

(1-way ANOVA: $\left.F_{3,84}=3.79, p=0.013\right)$. This was due to surface areas being lower for particles treated with a low catalyst concentration than for those treated with a high catalyst concentration (post hoc Tukey's HSD test, $p<0.05$; Fig. 1). Because no difference was observed when compared to the control, it is therefore likely that the difference in surface areas between nylon fragments was due to variation inherent to the stock nylon particles used in this study, rather than an effect of Fenton's reagent on particle size. The ATR-FT-IR profiles of all four plastic types were found to be insensitive to Fenton's reagent at each of the catalyst concentrations that were tested (see Fig. 2 for a comparison of control samples and plastics treated using the highest catalyst concentration). The spectra showed signature absorbance bands ${ }^{10}$ of each polymer type to be unaffected by the purification step, irrespective of the catalyst concentration (Fig. 2). Additionally, all of the reactions tested were completed in 10 minutes or less. This shows that all reaction intensities (low, medium and high catalyst concentrations) offer a marked improvement in time efficiency compared with previously published pre-treatment methods. ${ }^{10,18,19}$

Cole et $a l .{ }^{18}$ compared the efficiency of several methods for removing biogenic organic matter (BOM) to enable analysis of microplastics in plankton-rich seawater. The efficiency of acid $(\mathrm{HCl})$ and alkali $(\mathrm{NaOH})$ hydrolysis as well as an enzymatic (Proteinase-K) approach were evaluated (both with and without sonication). Of these approaches, enzymatic degradation was the most effective with $97 \%$ of organic matter successfully removed according to the authors. The total time for this multistep approach (including time taken to desiccate, incubate and sonicate the samples) was two hours and 55 minutes. An alternate 

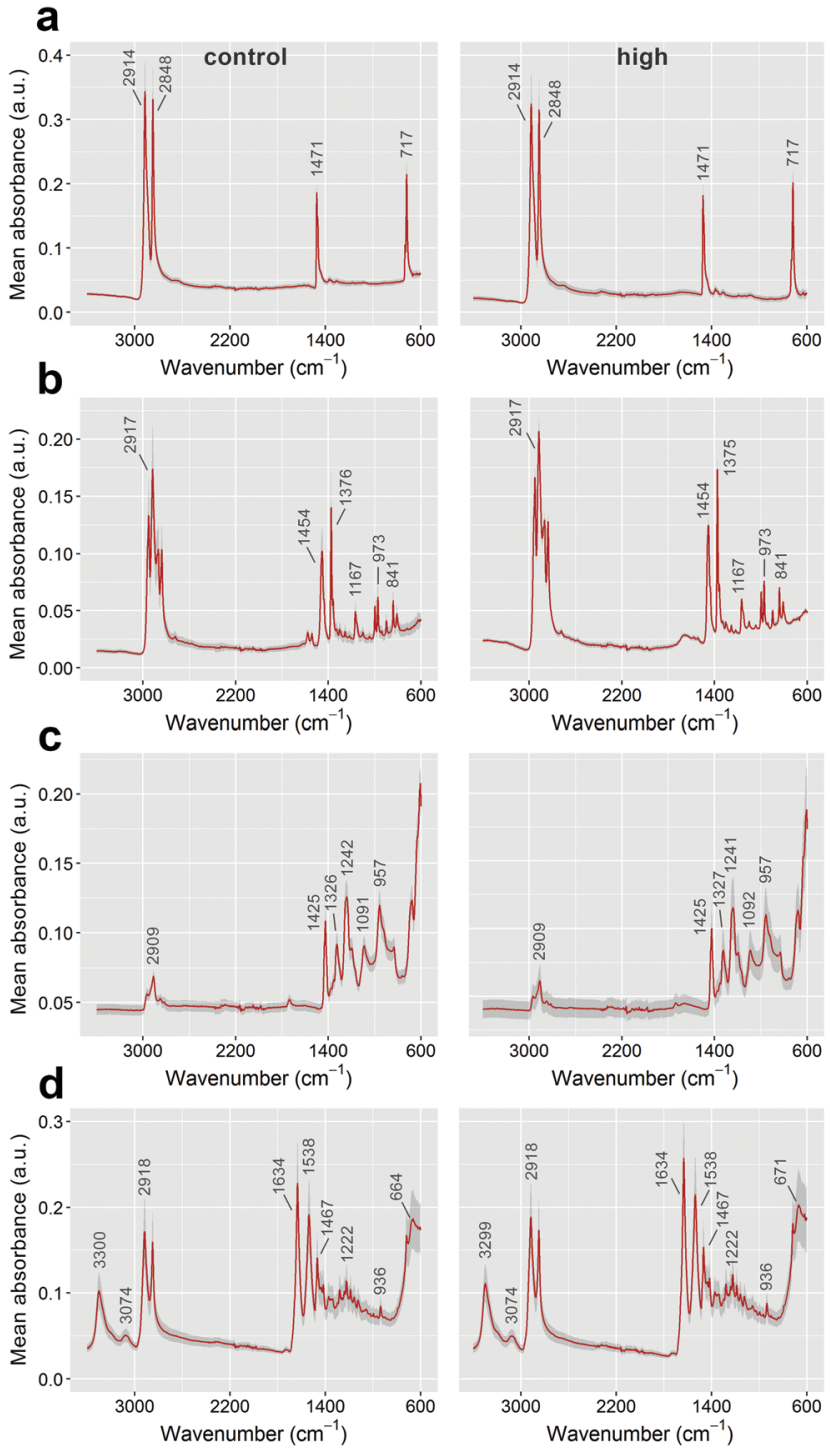

Fig. 2 ATR-FT-IR spectra of microplastics. (a) PE; (b) PP; (c) PVC; (d) nylon. Absorbance values are given as means $(n=3)$, with the $95 \%$ confidence interval indicated in grey. Spectra are shown for samples prepared either in the absence of Fenton's reagent ('control') or following exposure to a high reagent concentration (10 $\mathrm{mg} \mathrm{ml}^{-1}$ of ferrous sulphate).

study investigating BOM removal for the detection of microplastics compared the efficiency of seven-day exposures using either $30 \%$ or $35 \%(\mathrm{v} / \mathrm{v}) \mathrm{H}_{2} \mathrm{O}_{2}, \mathrm{HCl}(20 \% \mathrm{v} / \mathrm{v})$ or $\mathrm{NaOH}(20,30,40$ and $50 \% \mathrm{v} / \mathrm{v}){ }^{19}$ The use of Fenton's reagent negates the need for the prolonged exposure times required by all of these approaches. Additionally, there is no requirement for multiple sample preparation steps such as desiccation, physical homogenisation, sonication or multiple incubation stages for enzymatic degradation. ${ }^{18}$ However, some additional sample preparation steps (such as desiccation, homogenisation or secondary digestion) could be used in combination with Fenton's reagent if the present method proves ineffective (e.g. possibly in the case of examining solid biogenic samples, such as soils or CLO).

To assess the validity of Fenton's reagent for detecting microplastics in complex BOM-rich substrates, duplicate samples of biological activated anaerobic wastewater were examined. The medium-dose reaction (6.67 $\mathrm{mg} \mathrm{ml}^{-1}$ of ferrous sulphate) was selected as it provides a good balance between time-efficiency and reaction vigour, and no changes to microplastic size or spectra were observed (Fig. 1 and 2). Samples (total of 1 l) were collected using a telescopic sampling pole (Telescoop, Waterra Ltd, Solihull, UK) from the top $30 \mathrm{~cm}$ of the biological activated anaerobic stage at Severn Trent wastewater facility (Derby, UK). The wastewater was divided into $50 \mathrm{ml}$ centrifuge tubes (VWR) and centrifuged at $2038 \times g$ for $2 \mathrm{~min}$. The resulting pellets were treated with $30 \mathrm{ml}$ of Fenton's reagent, with the reactions completed directly in the centrifuge tubes. Each reaction was allowed to progress for 10 minutes, followed by a 10 minute cooling period prior to filtering. Duplicate negative controls were prepared by using ultra-high quality (UHQ) water. Once the reaction was complete, filtration and focal plane array-based reflectance micro-FT-IR imaging was undertaken following previously established methods (for example, Tagg et al.). ${ }^{10} \mathrm{~A}$ total of four microplastic fragments were identified in the wastewater samples, with no fragments present in the negative controls. Fig. 3 shows a false-colour image and an associated spectrum of a PE microplastic isolated from wastewater. While the signal-to-noise ratio of the spectrum was low in comparison with those measured ATR-FT-IR and reference microplastics (Fig. 2), the key identifying peaks were still clearly visible. ${ }^{10}$ The additional peaks in this spectrum could be due to accumulation of unidentified compounds on the polymer surface or because of refractive error associated with the reflectance micro-FT-IR analysis of unevenly shaped microplastics. ${ }^{20-22}$
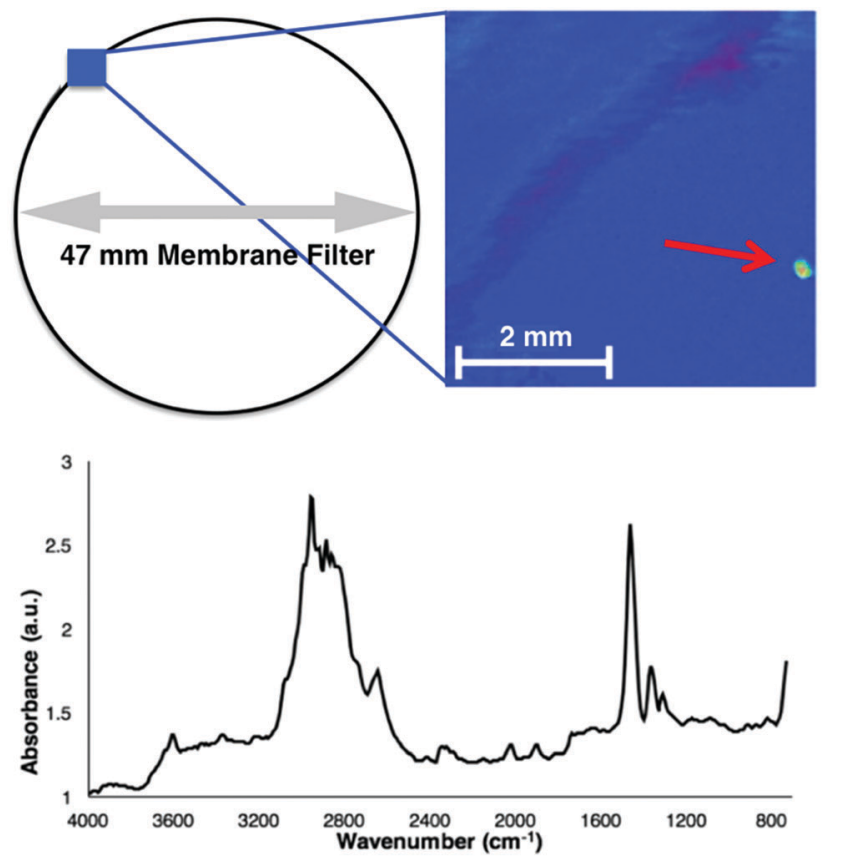

Fig. 3 (above) Membrane filter location and false-colour image of PE microplastic in wastewater, detected by focal plane array-based microFT-IR spectroscopic imaging following Fenton's reagent pre-treatment. (below) FT-IR spectrum of identified PE particle. 
In conclusion, our data demonstrate that Fenton's reagent is a very useful preparation method for the efficient and bias-free analysis of microplastics. Any of the catalyst concentrations employed in this study have the potential to improve upon current methods for isolating microplastics from wastewater or other complex media by reducing the exposure time from days or hours to $\sim 10 \mathrm{~min} .^{10,18,19}$ Our results also show that the method successfully enables the detection of microscopic polymers in field-collected wastewater. Therefore, compared with previously published protocols, using Fenton's reagent offers a simple, highspeed and low-cost method for processing microplastics present within environmental samples.

This work was funded by a NERC (Natural Environment Research Council) CASE studentship (NE/K007521/2) with contribution from industrial partner Fera Science Ltd, United Kingdom. The authors would like to thank Peter Vale, from Severn Trent Water Ltd, for providing access to the Severn Trent wastewater treatment plant in Derbyshire, UK.

\section{Notes and references}

1 R. C. Thompson, Y. Olsen, R. P. Mitchell, A. Davis, S. J. Rowland, A. W. G. John, D. McGonigle and A. E. Russell, Science, 2004, 304, 838.

2 D. Eerkes-Medrano, R. C. Thompson and D. C. Aldridge, Water Res., 2015, 75, 63-82.

3 M. Wagner, C. Scherer, D. Alvarez-Muñoz, N. Brennholt, X. Bourrain, S. Buchinger, E. Fries, C. Grosbois, J. Klasmeier and T. Marti, Environ. Sci. Eur., 2014, 26, 1.
4 S. A. Carr, J. Liu and A. G. Tesoro, Water Res., 2016, 91, 174-182.

5 S. Estahbanati and N. Fahrenfeld, Chemosphere, 2016, 162, 277-284.

6 S. A. Mason, D. Garneau, R. Sutton, Y. Chu, K. Ehmann, J. Barnes, P. Fink, D. Papazissimos and D. L. Rogers, Environ. Pollut., 2016, 218, 1045-1054.

7 F. Murphy, C. Ewins, F. Carbonnier and B. Quinn, Environ. Sci. Technol., 2016, 50, 5800-5808.

8 T. Hoellein, M. Rojas, A. Pink, J. Gasior and J. Kelly, PLoS One, 2014, 9, e98485.

9 M. A. Browne, P. Crump, S. J. Niven, E. Teuten, A. Tonkin, T. Galloway and R. Thompson, Environ. Sci. Technol., 2011, 45, 9175-9179.

10 A. S. Tagg, M. Sapp, J. P. Harrison and J. J. Ojeda, Anal. Chem., 2015, 87, 6032-6040.

11 X. Tao, J. Su, J. Chen and J. Zhao, Chem. Commun., 2005, 4607-4609.

12 H. J. H. Fenton, J. Chem. Soc., Trans., 1894, 65, 899-910.

13 A. Dehaut, A.-L. Cassone, L. Frère, L. Hermabessiere, C. Himber, E. Rinnert, G. Rivière, C. Lambert, P. Soudant and A. Huvet, Environ. Pollut., 2016, 215, 223-233.

14 V. Hidalgo-Ruz, L. Gutow, R. C. Thompson and M. Thiel, Environ. Sci. Technol., 2012, 46, 3060-3075.

15 M. D. Abràmoff, P. J. Magalhães and S. J. Ram, Biophotonics Int., 2004, 11, 36-42.

16 R Core Team, $R$ : a language and environment for statistical computing, Vienna, Austria, 2013.

17 F. De Mendiburu, Agricolae: statistical procedures for agricultural research. $R$ package version 1.1-2, 2009.

18 M. Cole, H. Webb, P. K. Lindeque, E. S. Fileman, C. Halsband and T. S. Galloway, Sci. Rep., 2014, 4, 4528.

19 M.-T. Nuelle, J. H. Dekiff, D. Remy and E. Fries, Environ. Pollut., 2014, 184, 161-169.

20 P. Bassan, H. J. Byrne, F. Bonnier, J. Lee, P. Dumas and P. Gardner, Analyst, 2009, 134, 1586-1593.

21 B. O. Budevska, Vib. Spectrosc., 2000, 24, 37-45.

22 J. P. Harrison, J. J. Ojeda and M. E. Romero-Gonzalez, Sci. Total Environ., 2012, 416, 455-463. 